\title{
A Survey Of Community Perception On Policy Acceptance Of Environmental Taxation In Nigeria
}

\author{
Iliya Garba ${ }^{1}$, Kennedy Gunawardana ${ }^{2}$ \\ MPhil/Ph.D. Student Faculty of Graduate Studies University of Colombo, Sri Lanka \\ Faculty of Management and Commerce, University of Sri- Jayewardenepura, Sri Lanka
}

\begin{abstract}
The paper examines what will motivate the public to accept a policy that will acknowledge environmental taxation in Nigeria. Most of the reviewed literature revealed that the public support for policy instrument is dependent on their trust and their confidence in others, hence, we argued whether political trust and interpersonal trust affect individual support for acceptance or rejection of environmental taxation. Survey technique was used and a close-ended questionnaire was administered to an individual to elicit their responses. The researcher applied Yaro Yamane sample size calculation formulae based on the number of Samples under discussion. The finding of the study reveals that political confidence, interpersonal trust, ethical beliefs and norms of people are the major key player in determining policy acceptance of environmental taxes.
\end{abstract}

Key words: Environment, Nigeria, Policy, Taxation

\section{Introduction}

Economists have long favored the use of taxes as an instrument for environmental corrections and protection. Economist analysis argue that, in a situation involving serious externalities taxes are the most effective mechanism for "getting the price right" (Lawrence 1994, Linda 2014).Environmental taxation have been discussed as one of the main mechanism to deal with environmental problems, a nonetheless instrument for this type have rarely been implemented because of policy acceptance is weak and the perception that environmental taxes are unfair and regressive, coercive and punitive. For this reasons, the adoption of new or higher environmental taxes has face resistance in some countries for example South Africa, New Zealand, Sweden (Sebestian 2013). A Large body of scholars such as ( Olson M 2013), asserted that many environmental collective action problems can best be resolved through the use of market-based policy 
instrument such as environmental taxation. Because they are cost efficient and because they tend to leave a certain amount of freedom of choice (Cox head and Chain 2011), stated that environmental tax is a policy issue that has generated a particular interest in recent years, which involves increasing taxes on the use of environment and reduction of taxes in other areas. There will be more willingness on the part of individuals and cooperate organizations to pay the tax because they will believe that their benefits derived from them since the tax being paid has something to do with their environment ( Fulletone 1996). An environmental tax is defined as: "any compulsory, unreciprocated disbursement to the government, levied on tax-bases deemed to be of particular environmental relevance", where the tax bases include energy products, motor vehicles, wastes, measured or estimated emissions, natural resources, etc. (OECD, 2013). The OECD also consider environmental taxation as an instrument for a sustainable economy, that make use of tax system to encourage a change of attitude for economic agents to reduce the negative impact that their industrial practices cause to the environment. Furthermore, according to (Jeze 2013), taxes are defined as a pecuniary payment, require from individuals through authority and without a counter party. According to Lawrence (2015), defined an Environmental tax as A tax whose tax base is a physical unit (or a proxy of it) of something that has a proven, particular negative impact on the environment." - the definition is exclusively based on the real physical unit of the tax.focus emphasis on the potential effect of a given tax in terms of its impact on costs and prices

Historically, environmental protection has primarily been based on state based environmental protection, such as legislation and ban. However, nowadays environmental degradation is increasingly perceived as being based on individual citizen or consumer choices, others argue that coercive and firm policies will solve the problem (wheel and Mol 2009), some advocate for measures primarily aimed at "giving" citizens towards his environmental behaviours e.g through enlighten or education(Dobson 2003).

However, it is one thing to claim and demonstrate the market-based instruments are (economically) efficient and it is quite another thing to gain public support for them. This 
has motivated scholars to into why some people tend to accept such environmental policy instrument, while other does not.

The aim of the paper is to explore Community perception of policy acceptance of environmental taxation. The study analyzes environmental tax and how it can be used to influence policy acceptance in the Nigerian context. Considering the numerous environmental problems

\section{Rationale for Environmental Taxes}

The main fundamental reasons for environmental taxation are to work with price system not against the price system and to allow the polluter's maximum flexibility to choose the most efficient way to achieve abatement goal in order to improve the structure of the taxes, for example by reducing tax concession for polluting activities. There exist a market failure in which market forces alone cannot provide enough environmental goods and service. Other environmental regulations are less effective in addressing the market failure than taxes and charges. Therefore, "polluter pays" principles as a rationale for environmental taxation as suggested by A.C Pigov (1920), that one person's actions may cause either benefits or costs to other members of the society. The existence of such social costs or benefits could be good reasons for government interference through the imposition of environmental taxes. Therefore good environmental policy is also good tax policy. In practice, environmental taxes seem to be the most attractive choice for most emerging markets. Because Collection is easier as it can rely on existing capacities and institutions

\section{Statement of the Problem}

While other developing countries have taken the initiative in environmental sustainability through taxations, Nigeria is lagged behind. Taxation can be a crucial market base instrument that can be used as synergy effort to move in this direction. As other countries have initiated a specific environmental taxes example South Africa, Malaysia, Vietnam just to mention a few. Nigerian governments have not made any effort despite an increase in environmental degradation, pollution from industries. Considering an increase in the 
government expenditure on health well-being of its people due environmental pollution by industries

The absence of any estimation of damage costs and lack of implementing best practices of environmental taxes as done in other countries is felt the need. It is desired that this will fill a void in an environmental degradation and environmental policy in Nigeria.

\section{Scope of the study}

The research could not cover everybody under discussion in the study; it is therefore, limited to Six thousand individuals in Nigeria. One thousand from each six geopolitical zones whose have shown their interest to participate in the survey.

\section{Objectives of the Study}

The main objective of the study is to examine what motivate peoples to accept policy towards environmental issues in Nigeria.

The specific objectives are:

1. To ascertain the extent to which the policy makers influence the acceptance or support of environmental tax

2. To ascertain the extent of individual's perception that that environmental taxes are unfair and regressive.

\section{Literature Review and Conceptual Frame work}

The main economic reasons for using taxes in an environmental policy is to bring the costs of pollution and other costs of using the environment which is called the externalities into the price of the goods and services produced by the economic activity. Internalizing external environmental costs is the main reasons for environmental taxes 
instead of regulations. The incorporate the cost of environmental service and damages directly into the prices of the goods, services or activities which give rise to them. These also help to implement the polluter's pays principles and to integrate economic, fiscal and environmental policies (EEA 2012).

A common argument for employing environmental taxes is that they are often comparatively economically efficient (Staner, Tietenberg 2013), clearly and important loadstar for politician and policy makers, however, it is questionable whether this criterion alone is good enough for adopting them. When designing policy tools, a decision maker constantly faces the challenges of carefully striking a balance between efficiency and legitimacy, as the level of direction, public policy support can be expected to have a measured impact on subsequent policy performance (Mattins2009). Furthermore, unless the measures display sufficient potentially broad public support, the suggested public instrument will likely not going to be advocated in the political sphere, and this will be rejected( Shapiro and Glynn 1999). For this reasons it is, therefore, necessary for society and its policy makers to understand the condition under which environmental taxes are considered legitimate among the public rather than be scared because of the word "tax". The intuition is that it is welfare improving to tax "bad" things high i.e. pollution and "good" things less. Because taxing bad thing is corrective and good things are distortionary.

Factors affecting individual's acceptance of environmental policy in general and acceptance of environmental taxes in particular. The researcher elaborates three major reasons or determinants for policy acceptance of environmental taxes in Nigeria. Thus are as follows:

i. political trust s a determinant of policy acceptance

ii. Values, Beliefs, and Norms as a determinant of policy acceptance

iii. Interpersonal trust as a determinant of policy acceptance

however, these are not the only factors that determine the policy acceptance, it is also apparently better to rely on peoples interest in the contents of their wallets than hoping 
for people to change their preference based on moral reasoning. Cost efficient is also one of the important determinants for the prospects of implementing environmental taxes (Elliot et al 1997, Torgler and Garcia Valinas2007).

The argument for environmental taxes is that, if a product or activity is made more expensive, people will respectively buy or do less of it. If the activity is associated with excessive environmental damage, this will reduce the environmental damage. It is obviously desirable to evaluate the extent to which this argument holds up in practice, the extent to which environmental taxes really do lead to environmental improvement. Evaluations of environmental taxes following their implementation are desirable not only to see how effective they have been in environmental terms, but also to learn lessons about how best to introduce them and to communicate their impact and value to policymakers (EEA 2009).

In Nigeria, these factors have played a very important role in policy formulation, because Nigeria is a complex country with many geographical Variations, multi ethnics, and religious diversity, for this reasons looking at these factors listed above,

\section{(I ) Political trust as determinant of policy acceptance}

According to (Uslanar 20021; Niklass2013) Asserted that people's propensity to support policy instrument is also affected by their political trust. The reason is that the more people trust the politician in the ("Parliament" and "the government"), the more likely they are to accept the policy broad up by them and environmental tax policy inclusive. This result is made comprehensible through two lines of reasoning. First, unless peoples trust in the competency of their Politician popularity i.e. the politician knows what is required to influence policy formulation which will lead to success the people will not be apt to accept the policy. Secondly, unless people trust that the political institution can and will deal with the revenues generated from the taxes in the righteous, effective, efficient and in a realistic manner by making the costs and benefits of environmental policy clearer. There will be less willing to also accept or support such tax. Furthermore, lack of accountability, trust, fairness, corruption, and participation may also affect the willingness of the public to support the policy. Unless if the public considers the 
authority implementing the instrument to be trustworthy to some degree, its support for the implementation tends to be low. Public support also depends on whether the instrument will be fair in its procedures and outcome, as well as the degree to which public has had a say in the implementation process (Jagers, and Hammer 2009).

\section{(ii). Values Benefits and Norms as Determinant of public support and acceptance}

The values beliefs and norms theory of environmental support (Stern P.C 2000), assumes that many behavioural activities are the result of a causal chain that start with personal value priorities, which lead to beliefs i.e ( general environmental beliefs; awareness of environmental consequences; ascription of personal responsibility for these consequences) and finally the formation of personal norms of behaviour public support may likely be low if these concept values were not taking into consideration by the policy makers.

\section{(iii) Interpersonal Trust as a Determinant of Public Support and Acceptance}

This factor has to do with the individual stage of a dilemma in term of decision making on environmental problems. Individual propensity to neglect cooperation in favor of adopting selfish behavior or selfish interest. This is due to the fact that most people may have a general disposition to cooperate, but this propensity is partly conditioned by their trust that the other citizens or involved actor will cooperate too. (Dowes 1980, et al Ostrom2005), individuals attitude to environmental taxes is tailored by their perception as to whether they trust in the cooperation of others. E.g First people will support environmental taxes while skeptical the likelihood that others will do likewise, i.e to act in the environmental friendly way of their own accord. One motivation for such behavior is that positive action is necessary to balance the negative effect of those acting selfishly. Second, the policy tools in itself are based on cooperation. Thus, if people instead perceive that their colleague citizens are dishonest and they doubt that people will comply with the environmental taxes they will less incline to support it (Hama $\mathrm{H}$ and Jaegers 2009). 


\section{POLICY ACCEPTANCE MODEL OF ENVIRONMENTAL TAXATION IN NIGERIA}

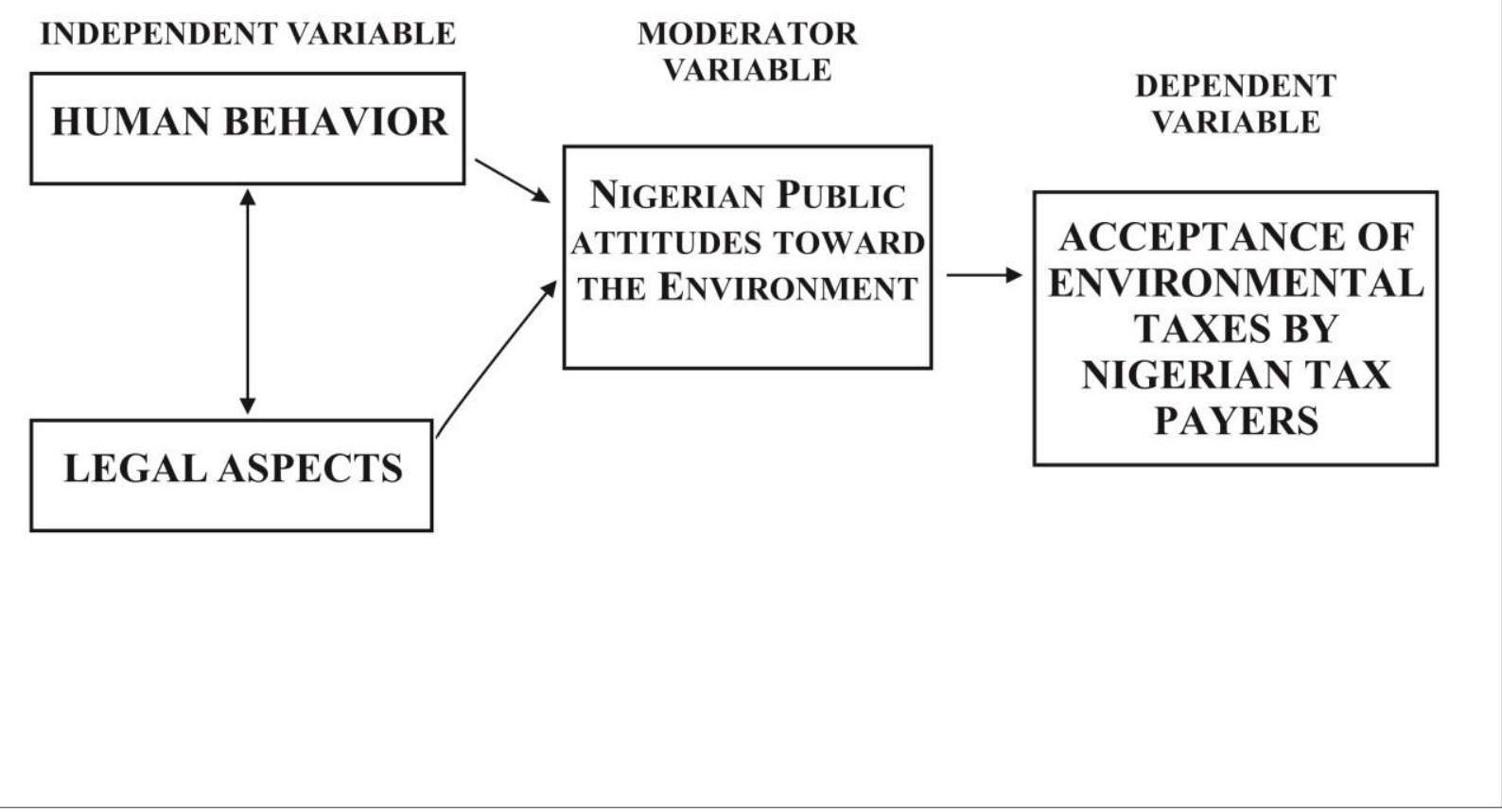

The model is designed to explaining the rationale for policy implementation as claimed by Chen Bao (2010), Thalman(2012) Figure one above show the Model. The model describes the position of environmental taxes. therefore tax payers in Nigeria have to comply with the tax laws of the country (including environmental taxes laws) they are three ways the tax payers comply to environmental tax laws. Thus are as follows $i$. Voluntary compliance ii. Forced compliance. iii. Noncompliance. From the above models, it can be now be tested using the suitable statistical method. Therefore the variables identified in the model are dependent and independent ( i.e acceptance of environmental taxes in Nigeria by the tax payers)

\section{Independent variables}


Human Behavior Aspects: which consist of (I). Future Quality of life Thalman and Chan (2010) were of the view that the love for having a better quality in the future will encourage environmental protection. However, from their study, it has been noted artificial inducement to encourage environmental protection such as environmental taxes is redundant. Therefore environmental taxes are needed to stimulate an effort to protect the environment through behavioral changes from an individual.

(ii). Self Actualization: from chang (2010) experience concluded that the protection of the environment will be successful if the public puts the "value" of environment higher than the monetary gain. By so doing public has to be enlightened about the value of the environment. Because unless the public is willing to put the environment above the financial benefits, the introduction of any form of taxes will be successful

(iii). unless the public has a positive attitude towards the protection of the environment, any attempts to introduce any environmental protection policies will fail including environmental taxation. Therefore this variable is related to "forced compliance" if certain are forced upon, there may not be a commitment for the public to support the policy.

(iv). Tax Mitigation: Gallo (2011), that corrective fuel surcharge policy will encourage motorist to use public transport or buy more fuel efficient vehicles. This implies that the tax payer may accept a certain new environmental tax law to reduce their current tax position.

Legal Aspect which consists of the following: (i). forced compliance, if Nigerian taxpayer understands the motive behind environmental taxation policies and laws. He could compel or forced to accept the policies or laws because he understands why compliance is good for him. Oliver et al (2011) found that willingness of house hold to pay taxes is influenced by the level of consumers understanding of issues concerning climate change. Therefore if the public did not understand why the need to protect the environment, any attempt to introduce any environmental protection policies (environmental tax inclusive) will fail. Any compliance to the laws is because the public 
is forced to comply. Fu (2010), states that the public involvement in green policy development is imperative. Any forced down policy is not acceptable.

(ii). Immediate incentives: Mewton(2010), found that public will be encouraged to accept the environmental taxes if the government will provide incentives such as tax deduction, exemption and appreciate the justification of public fund on the pollution matters. But Wilson et al (1990) asserted that the group of polluters is concentrated and well organized; while those who get from pollution control i.e the policy makers or government agencies are dispersed and unorganized. Thus the outcome is often inconsistency tax regime with exemption from the well organized group.

\section{Concept of Sustainable Development}

World Bank (2012), "sustainable development is about enhancing human well- being through time and society's ability to enhance or improve human well- being depends on the choices made or preference of individuals, firms, communities, and government on how to utilizes their assets"

Therefore, the ability of the nation to sustain a consumption flow (and therefore to be sustainable) depends on the change of its stock of assets or wealth. These assets may include natural assets, human assets, knowledge assets, man-made assets ex cetera. For this reasons ability to manage this asset well is very vital to achieving sustainable development. However, there limits to sustainability, particularly for environmental and social assets that enhance human well-being through their mere existence as well as indirectly through their contribution to production and material being.

\section{Methodology}

The population for this research work comprises of politician, individuals, and community leaders. They were chosen as a population of the research because the policy acceptance or rejection of environmental taxes will be decided by them. The target population for this study comprises of individuals who are 18 years and above. In view of the researcher in the ability to reach out to the entire population, we adopted the 
Yamane (1967) sample size calculation formulae based on the number of Samples under discussion. The sample size is derived using the statistical

Formula stated, thus:

$n=N /\left(1+N\left(e^{2}\right)\right.$

Where:

$\mathrm{n}=$ sample size

$\mathrm{N}=$ Population size (finite population)

$\mathrm{e}=95 \%$ Level of significance desired

Therefore, $\mathrm{n}=6000 / 1+6000 \times(0.05)^{2}$

$$
\begin{aligned}
& \mathrm{n}=6000 / 15 \\
& \mathrm{n}=400
\end{aligned}
$$

Using the above formulae and the total number of estimated number of 6000 people with an error limit of 5\% level of significance, we arrived at a sample of 400 is, therefore, consider adequate as the Minimum for this study.

Furthermore, a well organized closed ended questionnaire was designed and administered to respondents for the analysis. The spearman Rank order Correlation which is non parametric test is used to measure the degree of association between the dependent and the independent variables in this study. 


\section{Data Analysis and Discussion of Results}

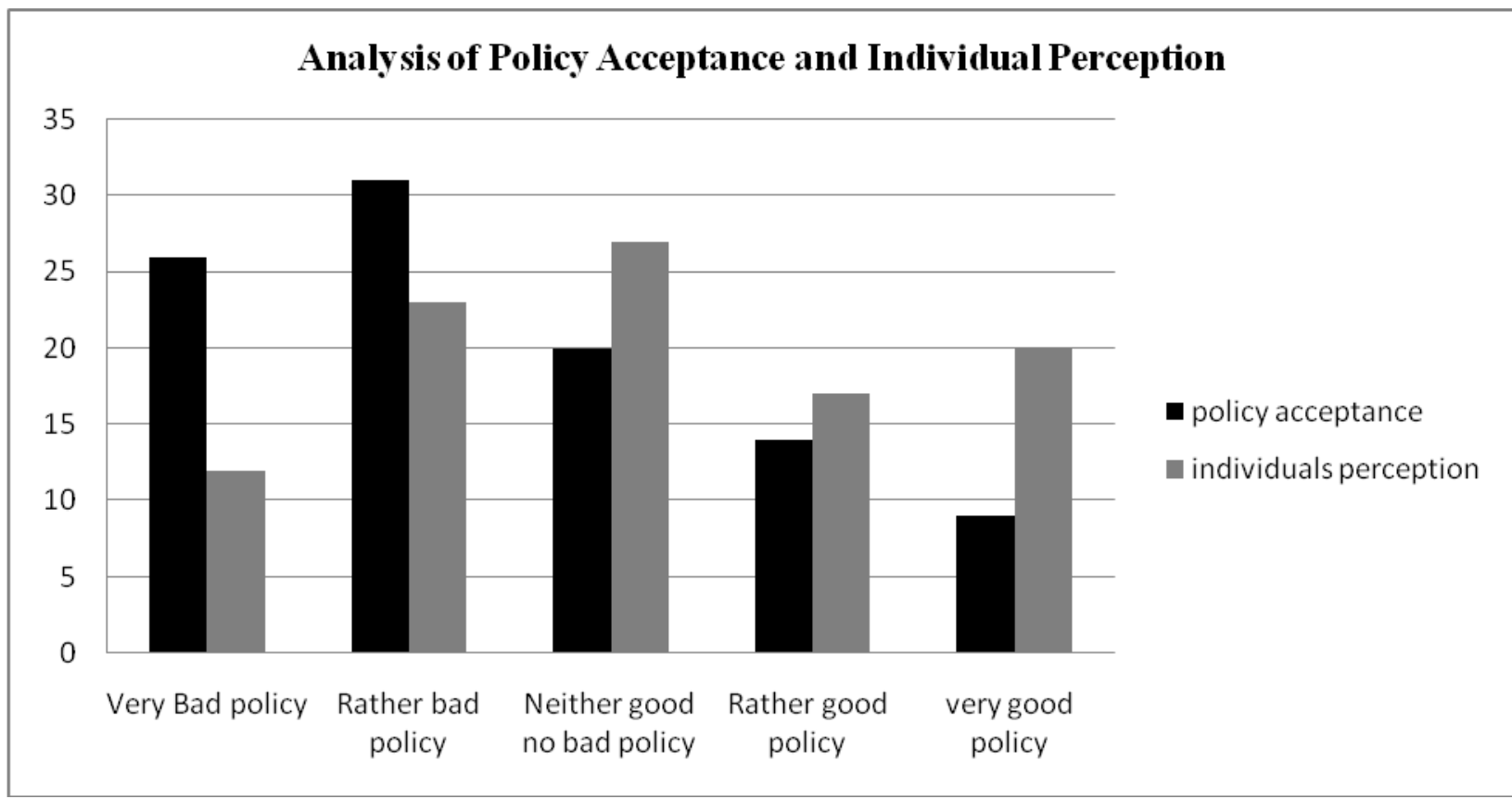

\section{SOURCE: Researcher computation 2015}

From the above line chart, the following can be deduced. Out of the 400 copies of a questionnaire administered, only 350 copies were retrieved with 50 copies not properly filled. Therefore, a total of 300 copies representing 75 percent were used for this analysis. 74 respondents and 94 representing 56 percent of the respondents are of the view that the policy is either bad or very bad policy that policy acceptance of environmental taxes is very weak. Nevertheless, regardless of this presentation by the respondents on the above subject matter, neither 60 respondents which represent 20 percent remain undecided that is they choose neither good nor bad policy another 54 respondents which represent 18 percent are of the view that the policy is good. But it is valid to conclude that their policy acceptance of environmental taxes is weak. Furthermore, on the same line, char two is representing the analysis of the respondent responses on why do individuals perceptions on environmental taxes is assertive? Out of the 300 respondents 40 respondents and 70 representing 23.3 percent of the total respondents, are of the view that the policy is either bad or very bad which concur with the assertion in the policy acceptance model on the behavior of an individual, where as 80 respondents which represent 26.7 percent remain 
undecided that is they choose neither good nor bad policy. Another 110 respondents which represent 36.7 percent are of the view that the policy is good.

\section{Conclusions and Recommendations}

On the basis of the results obtained it has been observed that governmental trustworthiness effects peoples support and acceptance of the new taxes towards and compliance with the public policy in general. It has also been demonstrated that trust has seriously affected people's attitude to environmental taxes. It has been noted that peoples tend to be more supportive of environmental tax if the trust their co- citizens, i.e if they believe that other will pay their share. Hence it may be a good idea, at least if trust is generally low, to implement only those taxes that are hard to evade. People tend to be more supportive of it and higher taxes- if they trust their politicians for the following two reasons.

i. To be supportive of environmental taxes, people must trust the politician will use the tax revenue in a transparent and well judicious manner.

ii. The tax public believes that the politicians are convinced that the tax will have its intended effect and it is considered sound policy choice.

Furthermore, government should come up with regulatory discipline by designing a tax that may coordinate environment and tax policies and programmes with the necessary political will aim at reducing pollution, and also the tax policy may be designed to place the tax burden heavily on those responsible for the particular environmental problem. 


\section{References}

Chang. (2010). Trade and the Environment: A political model of International Public Goods Problem, West Virginia: University Press USA.

Chain .B. (2011). Assessing the Willingness of the Public to pay in order to Conserve Urban Green Space. Journal of Environmental Health U, 4(2), Pp.432-450.

Coxhead, I., \& Chan, N. V. (2011). Vietnam's New Environmental Tax Law: What Will It Cost? Who Will Pay? (No. 561). University of Wisconsin, Agricultural and Applied Economics. Retrieved from http:/www.aae.edu/pubs/sps/pdf/stp/ap561.pdf

Dobson A. (2013). Citizenship and the Environment, Oxford: Oxford University press

Dowes, R. M. (2005). Social Dilemma. Annual review Journal of psychology, 31 (5), pp 169193.

Ekins, P., Andersen, M. S., Vos, H., Gee, D., Schlegelmilch, K., \& Wieringa, K. (1996). Environmental taxes: Implementation and environmental effectiveness. Publications Office of the European Union. Retrieved from http://www.geota.pt/rfa/docs/gt

EEA. (2011). Environmental Tax in Europe Implication for Income Distribution. EEA Technical reportno. 16/2011, ISSN 1725 - 223, Copenhagen: European environmental agency.

EEA (2009), Market Based Instrument for Environmental Policy in Europe. Technical Report No.8/2005, Copenhagen: European Environmental Agency.

Elliot, E. (1997). Political and Economic Determinant of Individual Support for Environmental Spending. Journal of Environmental Management, 5(1), pp 15-27.

Fullerton, D., \& Metcalf, G. E. (1997). Environmental taxes and the double-dividend hypothesis: Did you really expect something for nothing? (No. w6199). Cambridge: National bureau of economic research.

Fu. (2010). The Chinese Path of Rule of Environmental Law: Reflection and Exploration, China Environmental science press.

Grubb, (2014). The Green house effect: Negotiating Targets, Royal Institute of International affairs, London: IMF, Fiscal Affairs Department.

Glynn, C.J. (1999). Public Opinion and Policy Making. Boulder, co USA: West view press.

Hammar, H. \& Jagers S.C. (2009). Perceived Tax Evasion and the Important of trust. Journal of Social Economics, 38(6,) pp238 -245.

Jaze, T. (2013). Taxation and the Control of Externalities. Journal of American Economy Review, 64(3), Pp $462-46$.

Lawrence, K. (2015). 6TH International Conference on Tax Dialog France Paper Presentations.

Lawrence H. \& Goulder. (1994). Environmental Taxation and the Double Dividend Cambridge : National Bureau of Economic Research. 
Linda, S. (2014). Environmental Fiscal Reform in Namibia a Potential Approach to Reduce Poverty?, Journal of Environmental and Development, 21 (2), pp 219- 24.

Matins, A. (2009). Issues in the Design of Environmental Excise Taxes. Journal of Economic perspectives, $8(1$,$) pp 133-15$.

Meutien B. (2010). My space: Government, Individuals, Carbon Emission, Environmental, and Planning. Society and space journal, 28(2. pp 341-362.

Niklas, H (2013). Should we trust in value? Explaining public support for pro- Environmental Taxes. Journal of Sustainability, 5(5), pp 201- 22.

Oliver, H. (2010). The Moral Foundation of trust, Cambridge, UK: University press.

Ostrom, M. (2013). Understanding Institutional Diversity; Princeton NJ. USA: Princeton university press.

Organization of Economic Corporation and Development (OECD). (2011). Paris: Economic Instrument for Environmental Protection OECD. 